\title{
The Analysis of the Business Pattern of Online Community and Its Value
}

\author{
Zhiyuan $\mathrm{Ge}^{1}$ Shuping Mao ${ }^{1}$ Lili Sun ${ }^{1}$ \\ ${ }^{1}$ School of economic and management, Beijing University of technology, Beijing, \\ 100124, P. R. China
}

\begin{abstract}
With the number of Chinese Internet users is growing rapidly, Internet is building an extensive network of community, and people begin to find their homogeneous groups through a variety of ways on the network, under the context, online communities formed. So the business pattern of online community is discussed here. How can the online community use the strong cohesion and viscosity of the community members on the platform to develop its commercial value and choose what kind of business pattern? All of these questions are worthy exploring and even offer some improvements of SNS community according to the technology and social development, which may be useful for other types of community development.
\end{abstract}

Keywords: Online communities, business pattern, SNS community

\section{Introduction}

The internet is establishing a huge network society-community. There are 1.31 million independent sites and $80 \%$ of them have their own community by 2007.6 ${ }^{[1]}$ A lot of communities are becoming more popular to attract the risky investment. ${ }^{[2]}$ ESN as a new type of ecommerce will bring a new profit model and Some researchers analysis how to get a profit with the online community. ${ }^{[3][4][5]}$
The development of online community is so fast that become one of the best applications in the internet in 2008, the SNS community as a new type in the online community made large contributions at that time. ${ }^{[6]}$

In order to make sure the developing direction of online community based on its developing history and the profit model of the online community, it's necessary for us to focus on the whole online community in the internet.

\section{The business value chain of online community}

The network effects become more and more important. The business value of online community can transform the communication of user, shopping, entertainment into a kind of potential commercial activities and make them implemented to get the benefit. It mainly displays in three different sides: online marketing value, e-commerce value, Wireless value-added, see Fig. 1.

\subsection{Online marketing value}

1) The development of the online marketing

According to the mature of the development of the internet technology and the low cost of the internet, the corporations, associations, organizations and individuals can connect with each other to share the information all over the world. So it is more and more popular to be focused on 
due to the advantage of the internet. Online marketing was created at that time. It denotes the whole process which is that the organizations or individuals hold a series of marketing activities about the products and services based on the character of network communications to let their needs satisfied.

There is a fundamental change happened on the marketing idea of the online marketing which is based on the internet, so the platform and the way are becoming more and more varied. The processing is: Portal times, Searching engine media age, Community interaction age.

These three kinds of advertisement are existed at the same time during the process of the network marketing. Unfortunately, the advertisements at that time just caught the effect of the appearance but lack of accurate conception, so that these advertisements are just suitable for the common consuming.

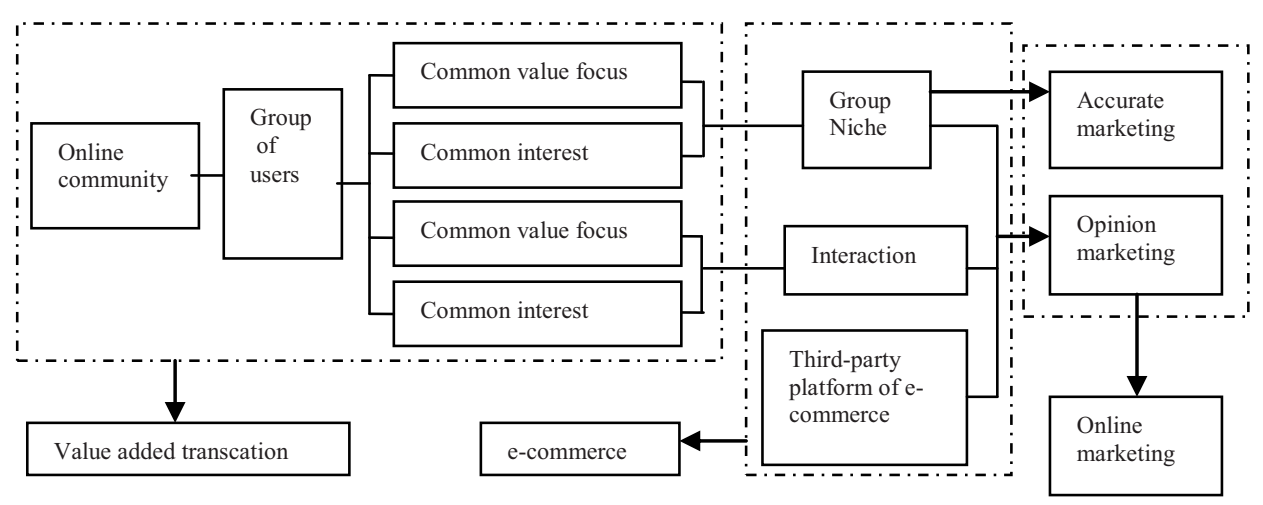

Fig. 1: The commercial value chain of online communities.

\section{2) The character of the network} marketing of the community

The commercial value of the network marketing depend on the work of the Advertisers, they usually focus on a group of customers who are interested in their products, according their speed of live, their requirements to produce and improve their own products or service to achieve the success of the business work. The character of the community marketing is as follows:

(1) Niche promotes the accurate investment of the advertisement.

While network community has a huge group of people who get strong cohesion and viscosity, the users gather into a certain kind of niche because of the value tendency and the interest. Here, there are two kinds of focus actually: people focus and the time focus.

(2) Interactive marketing become the bright spark.

(3) Delivering the feeling with each other can strong the reputation value.

\subsection{The e-commerce value}

Along with the advanced online commerce, more and more people depend on the supplier who offer the online business service so that there are more and more people consume in the internet and are used to trade in the internet. The quick development of taobao and the increasing of the volume of the online trade indicate that there is a fierce transaction demand in the internet, this transaction demand exited between the users, between the users and the 
corporations, between the corporations, etc. $^{[1]}$

\subsection{Wireless value-added}

Until 2009, the number of the users in WAP in China is nearly 200 million and the number of the WAP sites which have the independent domain name is about 500 thousand. The high-speed Growth period of WAP is coming and a lot of intelligent mobile-phones appear with the community function.

\section{The business pattern of online community}

Business pattern is a kind of definition group which contains a series elements and the relationship among them and can reflect the online marketing value, it represents a certain entity's business logic, including the value offer to customers and the inner structure, the network with the partners, the Profitable way of the relationship and all that are necessary elements to incomplete the value. ${ }^{[7]}$

Usually, there are nine kinds of business pattern existed in the corporation: value focus; target customer group; channel of distribution; the relationship with the clients; distribution of the value; core ability; network with partner; structure of the cost and the profit model.

The business patterns of online community usually focus on the Virtual Economy. Comparing with the real economy, there are some differences: the rituality of the online sits and the uncertain of the environment. So we can't copy the business pattern of real economy to implement it for the business pattern of the online community, see fig $2 .^{[8]}$

\subsection{Value focus}

Online community keeps a tense relationship with the real world in the certain angle; the realness is more and more obvious. So it offers a great place for users to express themselves and release themselves. During the period, simple online community can't satisfy the demand of the users due to their diversity requirements so that the value focus is changing into the exploration of profit transcription based on the attracting users simply.

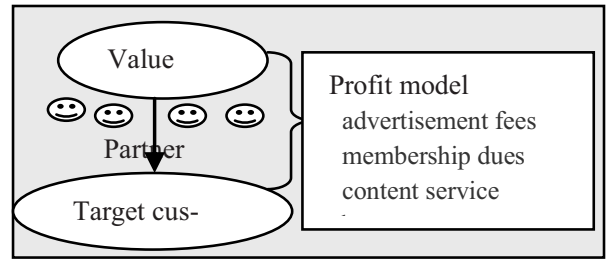

Fig. 2: The business pattern of online community.

\subsection{Target customer group}

Table 1 below indicates the group whose age is above 18 and has income is the main customer group, TGI index showed the same result.

Even though the main customer group is the group whose age is above 18, but different communities should focus on the different group in detail, such as renren is focus on the students and happy web is focus on the young employees, etc. So it's very important to fix the target customer group.

\subsection{Channel of distribution}

The partners of online community contain Internet content providers, wireless transaction providers, Co-shopping platform, Co-payment platform and the Cooperative logistics platform, etc. It's better for online community to integrate its own resource of resource vertically, expand the range of the transaction, service the customers and develop the profit model, such as zhifubao is used in a lot of payment system of the online 
community due to its high degree of safety and Consumer trust.

\begin{tabular}{|c|c|c|}
\hline & $\begin{array}{c}\text { Seepage } \\
\text { rate (\%) }\end{array}$ & TGI $^{(3)}$ \\
\hline 18 below & 14.5 & 76.1 \\
\hline 18 -24 students & 9.9 & 107.0 \\
\hline 18 -24non students & 23.0 & 101.9 \\
\hline $\begin{array}{c}\text { Ordinary revenue group } \\
\text { with the age above } 25^{(1)}\end{array}$ & 29.9 & 102.2 \\
\hline $\begin{array}{c}\text { High revenue group with } \\
\text { the age above 25 }\end{array}$ & 22.7 & 114.4 \\
\hline
\end{tabular}

Notes: (1) above 25 years old, individual income below $3000 \mathrm{rmb}$ per month and family income below $5000 \mathrm{rmb}$ per month;

(2) above 25 years old, individual income above $3000 \mathrm{rmb}$ per month, family income above $5000 \mathrm{rmb}$ per month;

(3) target group index, can reflect the disadvantage and the advantage of the target group in a certain researching arrangement and its average is 100 .

Table 1: The audience of online communities.

\subsection{The profit model}

Advertisement is the main profit resource at the beginning of the online community. The profit models become diversity after the high development of the online community. The main profit resources of the online community are as follow:

(1) Advertisement fees. Nowadays, more and more corporation begin invest the advertisement on the online community. Besides, whether the corporations invest the advertisement on the online community or not depend on the netizens who if belong to the target customer group. So this kind of profit model is not suitable for all of the online communities. ${ }^{[9]}$

(2) Membership dues. The online community will charge different membership dues due to different rank of the member. Such as Women dating community (http://www.21cn.com) divides the members into three ranks: free; ordinary; VIP. It won't charge to the free members, but $5 \mathrm{rmb} /$ month to ordinary members and $15 \mathrm{rmb} /$ month to VIP, it offers different service to different ranks. These membership dues mainly focus on the netizens who have the strong demand of this service. So this kind of profit model gets the limit to be popular. When the members of online community have strong demand and trust, it's suitable to charge the membership dues. ${ }^{[10]}$

(3) Content service charges. Online community found another to charge to netizens due to offering the different content service. For example, the community called

"rongshuxia"(http://www.rongshuxia.com) charge for $50 \mathrm{rmb} /$ year because of the every Message Board,20 rmb/month because of recommended place of each word in the index page, $240 \mathrm{rmb} /$ year because of the Internal mail. This kind of profit model still depends on the trust of the members of the online community and the value of the offered service.

(4) Transaction fees. Online communities charge the netizens or obtain some commission due to the transaction information. The transaction fees are the main profit model of the Trading community, but it's hard for those non-trading community to get profit from it. There are two reasons: first, the amount of transaction of $\mathrm{C} 2 \mathrm{C}$ community is limit; second, the communities lack of efficient mechanism of trustful safety.

In essence, the profit of online community comes from netizens and the added value which they bring to. So netizens are the main part of the online community. Even though the scale enlarges, the time and energy of theirs are limit, so netizens just join some communities selectively. So it's necessary to think about the strategy of development while choose the profit model. 


\section{Case analysis: SNS community}

\subsection{The business pattern of SNS community}

SNS (social networking services) helps people to create social network for the internet applied services specially. ${ }^{[11]} \mathrm{SNS}$ service make the communication among users more vividly with the program of friends sharing and entertainment interaction, satisfy the requirement of users. ${ }^{[12]}$

Here is the business pattern of SNS community according to the characters of the business pattern of online community (fig 3).the core value of SNS is to offer multi-functional entertainment and making friends platform; its target customers are the young employees and students who are good at accepting the new stuff and have no time to maintain the friendship, SNS community can transfer the real friendship into the network to satisfy their needs.

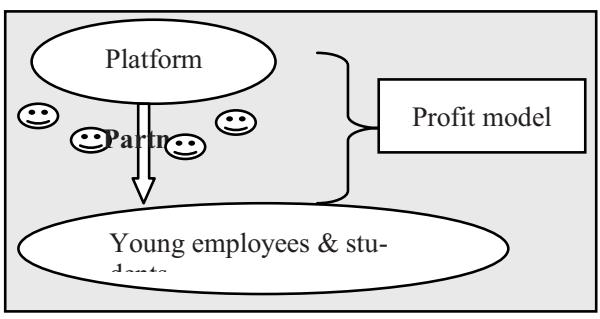

Fig. 3: The business pattern of the SNS community.

\subsection{The profit model analysis of SNS community}

The profit model of SNS community include advertise, e-commerce of community, testing of the corporation information, plug-ins of third-party and wireless value added service, as follow (fig 4). Advertise is the main profit model among the five ones, e-commerce of community is the most potential model, some of communities begin to explore it. Online communities co-work with the suppliers of plug-ins of third-party and get the benefit from it. Testing of the corporation information and wireless value added service contribute little comparing with the former models, however, they have a bright future according to the acceptance of community value from corporations and the development of $3 \mathrm{G}$ network.

\section{1) Advertise analysis}

There are three patterns of advertise besides the traditional page advertisement.

(1) The average clicks of the online Brand advertising is $0.14 \%$, and social networking site is famous for the low despondences. However, SNS may allow the individuals publish the advertisement, let them plug some advertisement on their own pages to gain profit, users also can invite the advertiser to buy the place on their page to gain profit from it after negotiating the time and fees, SNS get a certain part of the service fees, this will inspires more users to join it.

(2) Develop searching technology in time, expand the AdWords truncation. The success of Google AdWords shows the perspective of advertise pattern. For example, Google AdWords can get to know what the people are searching, what they thinking, what they wanting to learn and display the relevant advertisement. ${ }^{[13]}$ However, there is a problem about the delay; people can't get the information in time. So SNS can develop the advertise service which can show as soon as possible and be more sensitive to the time with the searching data.

(3) Data mining and database marketing. The original purpose of SNS is to make friends, record their own view and discuss publicly, so it's much more real to evaluate the altitude of users depend on a certain event with searching technology, but the information noise and the huge amount of it make the result much more unclear. SNS can search and 
collect this kind of information based on the data analysis and mining truncation to offer some corporations or institutions which are interested in it this kind of consulting service.

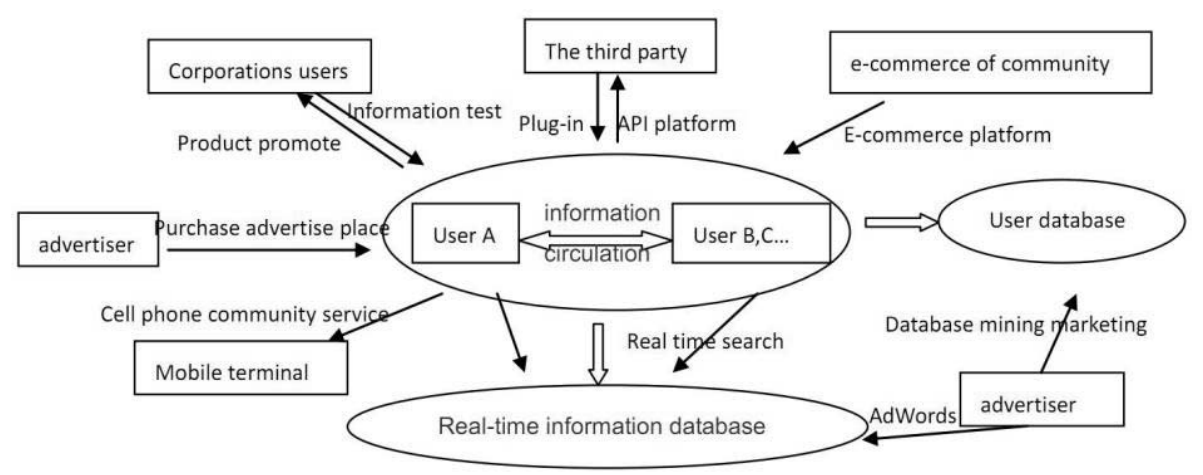

Fig. 4: The profit model of SNS.

\section{2) The e-commerce of community analysis}

One certain researching data shows that $83.7 \%$ users will check the evaluation of what they will buy on the relevant community to save the cost. The e-commerce of community is created based on the community content and users.

There are two kinds of pattern of ecommerce of community. First, B2C pattern: SNS offer the e-commerce service as a supplier. Compare with the character of other B2C pattern, there is a certain group of community users who have the common interest and hobby because of the content and construct of the SNS community, and the users usually keep the real friendship with each other, so the trusty is becoming stronger. Second, SNS community attracts the businessman to join the community ecommerce as a platform. These two patterns are developed based on the community users; e-commerce must affect the fairness of the content and service. So the online community should choose the suitable pattern in accordance with their own ability and situation of development.

\section{3) The benefit analysis of the plug-ins of the third party}

SNS sites begin to pursue API to gain profit which means allows the third party to create APP on their own sites for the user. This kind of open platform can satisfy the needs of users and let SNS community obtain more users and stronger viscosity.

\section{4) Corporation user analysis}

Corporations can create brand page and certain kinds of brand group on SNS community which belongs to the corporation; they also can send all kinds of information about the new products and sales promotion to users based on the SNS community, because the timeliness and share of SNS can deliver the information to the relevant group. It's better to maintain the cognition of the brand and the trusty of users. So it's very important to create a monitor system to prevent some rumor expanding on the internet.

\section{5) Wireless truncation analysis}

$3 \mathrm{G}$ is the abbreviation of 3rd Generation, means the third Mobile communication technology which can process a lot kinds 
of media types, such as the pictures, music and video.

\section{Conclusions}

The paper discusses the character and the form of expression of the business value of the online community, then talked about the difference between the online economic and the real economic based on the elements of the common business pattern. All of the business patterns have their own characters according to the service, at the end, this paper chose SNS community, created a model for it and analysis it.

\section{References}

[1]. Alexander Osterwalder, Yves Pigneur. An e-Business Model Ontology for Modeling e-Business, $15^{\text {th }}$ Bled Electronic Commerce Conference e-Reality: Constructing the eEconomy Bled,Slovenia. 2002.6

[2]. http://hi.baidu.com/skyscrep/blog/ite $\mathrm{m} / 1 \mathrm{dba} 34 \mathrm{a} 85 \mathrm{a} 1 \mathrm{cefb} 2 . \mathrm{html}$

[3]. Zhang Tingting, Yuan Lei.the analysis of the business pattern catalogue based on "3-4-8"system[J]. Central University of Finance and Economics academic journal. 2008(02):23

[4]. Cai Jian, Wang Haiyan, Wang Zhijun.the business value of online community[J].Beijing university business evaluation. 2007(4):26

[5]. Rappa, M. Managing the digital enterprise - business models on the Web

[6]. http://market.c114.net/187/a348867. html

[7]. Gao Gongjing.the interaction of BBS virtual community[J].China software science.2008(05)

[8]. Qiu Han,Tian Lijun.the connotation of the virtual community and the created organized path[J]. Central South University academic jour- nal. 2006.8

[9]. Manuel astells.Computer Networks as Social Networks:Collaborative Work, Telework and Virtual Community, Annual Reviews of Sociology,2003

[10]. Gao Gongjing. The interaction in the BBS virtual community [Z].the graduated paper of master degree from Shandong university.2005.4

[11].http://baike.baidu.com/view/8258.ht $\mathrm{m}$

[12]. iResearch. The third China online community research report.2007.3

[13]. Yuan Lei. The research of catalogue problem of business pattern[J],China software science,2008.5 